\title{
Long-term sustainability of a worksite canteen intervention of serving more fruit and vegetables
}

\author{
Anne V Thorsen ${ }^{1, *}$, Anne D Lassen ${ }^{1}$, Inge Tetens ${ }^{1}$, Ole Hels ${ }^{1}$ and Bent E Mikkelsen ${ }^{2}$ \\ 'Department of Nutrition, National Food Institute, Technical University of Denmark, Mørkhøj Bygade 19, \\ DK-2860 Søborg, Denmark: ${ }^{2}$ Nutrition \& Public Food Systems, Technical University of Aalborg, Denmark
}

Submitted 12 August 2009: Accepted 31 March 2010: First published online 6 May 2010

\begin{abstract}
Objective: To analyse the 5-year sustainability of a worksite canteen intervention of serving more fruit and vegetables $(\mathrm{F} \& \mathrm{~V})$.

Design: Average F\&V consumption per customer per meal per day was assessed in five worksite canteens by weighing F\&V served and subtracting waste. Data were collected by the canteen staff during a 3-week continuous period and compared to data from the same five canteens measured at baseline, at end point and at 1-year follow-up. The intervention used a participatory and empowering approach, self-monitoring and networking among the canteen staff, management and a consultant. The method focused on providing ideas for increased F\&V for lunch, making environmental changes in the canteens by giving access to tasteful and healthy food choices and reducing the availability of unhealthy options.

Setting: Five Danish worksites serving from 50 to 500 meals a day: a military base, an electronic component distributor, a bank, a town hall and a waste-handling facility. Subjects: Worksite canteen managers, canteen staff.

Results: Four of the five worksite canteens were able to either maintain the intervention or even increase the consumption of $F \& V$. The average increase from baseline to 5-year follow-up was $95 \mathrm{~g}$ per customer per meal per day (18, 144, 66, 105 and $141 \mathrm{~g}$, respectively). On average, the five canteens at the long-term follow-up had an F\&V consumption of $208 \mathrm{~g} /$ meal per customer.

Conclusions: The present study indicates that sustainability of $F \& V$ is possible in worksites where the participatory and empowering approach, self-monitoring, environmental change, dialogue with suppliers and networking among worksite canteens are applied.
\end{abstract}

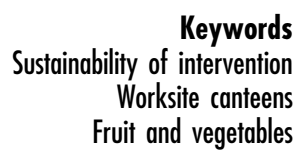

A poor diet and physical inactivity are linked to a number of diseases and disorders and are estimated to be among the main causes for the growth in overweight and obesity among the adult population. Increasing the intake of fruit and vegetables $(\mathrm{F} \& \mathrm{~V})$ is considered to be likely to reduce the burden of chronic diseases worldwide ${ }^{(1-4)}$.

The worksite is a unique setting since it reaches a large proportion of the adult population including those unlikely to engage in a preventive health behaviour programme ${ }^{(5-8)}$. The settings approach to promote healthy eating has been growing in importance ever since the Ottawa Charter for health promotion was adopted in $1986^{(9)}$. But since the Charter was adopted, it has been reshaped by many groups and individuals. There is evidence and also a framework from the literature reflecting on more critical ideas and action to help make health promotion more sustainable by targeting the interventions to the specific settings ${ }^{(10-13)}$.

A number of intervention studies at worksite settings have shown that it is possible to increase $\mathrm{F} \& \mathrm{~V}$ intake among employees ${ }^{(14-18)}$. The same conclusion is found in systematic reviews analysing the evidence on effectiveness and programmes promoting $F \& V$ intake in adults $^{(6,19,20)}$, but little is known about the long-term persistence of these changes, especially after the intervention has ceased. An initial implementation success does not necessarily predict a sustained effect of the intervention $^{(21)}$. There seems to be a lack of consensus about the conceptual and operational definitions of sustainability in the literature ${ }^{(5,6,8,10,12,22,23)}$. The concept of sustainability refers to the continuation of programmes ${ }^{(11)}$.

The original ' 6 a day' Worksite Canteen Model Study investigated the effect of a 6-month intervention on the F\&V consumption in five Danish worksite canteens. The original intervention was based on a participatory and empowering approach, self-monitoring and included networking among canteens. Results showed significant increases for all five canteens from baseline to end point, and this increase was found to be either maintained or 
increased (for the bank and the waste-handling facility) after a 4-month follow-up period ${ }^{(16)}$.

The objective of the present study was to return to the same worksites 5 years after the F\&V intervention initially started and analyse the long-term sustainability of the intervention.

\section{Materials and methods}

\section{Worksite recruitment and characteristics}

The canteen managers at the five Danish worksites who participated in the ' 6 a day' Worksite Canteen Model Study in $2001^{(16)}$ were asked by e-mail to participate in the 5-year follow-up study in 2006. All five canteen managers agreed to participate. As previously described ${ }^{(16)}$, the worksites were initially selected to vary with respect to employee profile (gender and age) and occupation (sedentary/physically exacting work). Regarding the worksite characteristics, data are obtained by interviewing the management and the canteen managers at the worksites. The number of customers at the worksite canteens was obtained from the baseline assessment in $2001^{(16)}$ or from the 5-year followup assessment in 2006.

\section{Monitoring the consumption of fruit and vegetables}

The 5-year follow-up data collection consisted of 3 weeks (Monday-Friday) of daily and continuous weighing of all $\mathrm{F} \& \mathrm{~V}$ consumed at the worksite canteens, as well as measuring the exact number of customers each day. In order to avoid seasonal variation of $F \& V$ intake, the data collection was conducted in the same months as the baseline in the intervention study (January-February). Therefore, the data collection was conducted exactly 5 years after baseline monitoring and 4 years and 4 months after end-point monitoring.

The data collection procedure was the same as the '6 a day' Worksite Canteen Model Study. In brief, the canteen staff were given the responsibility for measuring the consumption of F\&V and the exact number of customers. The records were divided into five weekdays and provided the listing of all $\mathrm{F} \& \mathrm{~V}$ that were prepared for serving. Furthermore, the records were divided into four meal categories that were weighed individually, because typically these dishes were prepared separately or at different periods during the working hours: hot dishes, cold dishes, salad bar and fresh fruit plus vegetable-based snack. The amount of F\&V not sold was deducted so that the average amount of $F \& V$ per lunch meal served per customer per day could be calculated. The number of customers was counted at each worksite in different ways depending on the worksite and its meal service system, either by counting using the cash register system or by counting trays. All the completed records were checked by the main author (A.V.T.) shortly after the 3 weeks of data collection and low or high records were examined for discrepancies.

\section{Method developed and performed at the original ' 6 a day' intervention study}

In the original ' 6 a day' Worksite Canteen Model Study, the canteen staff and management in five worksites were involved in defining the scope of activities and implementation $^{(16)}$. The canteen staff and management worked closely with the project team. The project used the tools of continuous quality improvement as a background construct, including canteen staff involvement and ownership and problem solving driven by measurable data ${ }^{(24,25)}$. Baseline measurements (grams of total F\&V consumption per lunch meal per customer) were followed by $8 \mathrm{~h}$ training, goal setting and strategy development by the staff and managers at each canteen. End-point measurements were performed 6 months after the beginning of strategy development, and follow-up measurements were performed within 1 year from baseline ( 4 months from end point). After the baseline measurements, a period of 2 months was spent preparing the F\&V intervention, goal setting, deciding on F\&V strategies and running courses for the staff. The 6-month intervention was followed by a 4-month period of no $\mathrm{F} \& \mathrm{~V}$ measurements before the 1-year follow-up was conducted. Furthermore, during the period of intervention, achievements at the canteens were shared in short newsletters and the canteen managers were encouraged to network with other canteens managers in order to share ideas and support each other.

\section{Statistics}

In order to test differences in intake between points in time (baseline, end point, short-term follow-up and long-term follow-up), a repeated measures ANOVA was performed with $F \& V$ intake as the dependent variable $(\mathrm{g} /$ meal per customer), canteen sites (military base, electronic component distributor, bank, town hall and waste-handling facility), and points in time (baseline, end point, 1-year followup and 5-year follow-up) were evaluated as independent fixed variables. Both main effects and interactions were evaluated. Statistical comparisons between points in time within worksites were performed by pairwise $t$ tests under repeated measures ANOVA. Spatial power was initially used as a covariance structure allowing for different distances between points in time. As the use of compound symmetry made no difference compared to spatial power and had the advantage of a lower Akaike's Information Criterion, compound symmetry was chosen as the covariance structure in the final model ${ }^{(26)}$. Homogeneity of variance and normal distribution of residuals were investigated by plots and histograms of residuals. Shapiro-Wilk's test for normal distribution was performed. Statistical analysis was performed using the procedure 'MIXED' in the Statistical Analysis System software package, SAS Enterprise Guide version 3.0 (SAS Institute Inc., Cary, NC, USA). Descriptive data are 
presented as means and standard deviations and results are presented as means with their standard errors.

\section{Results}

\section{Workplace characteristics}

The characteristics of the worksite regarding the profile of the employees are shown in Table 1. All worksites had in-house food service facilities and served from 50 to 500 customers on a daily basis. The worksites were a military base, an electronic component distributor, a bank, a town hall and a waste-handling facility. At two worksites, the majority of the employees were women (the bank and the town hall), two worksites had a majority of employees under 40 years of age (the military base and the electronic component distributor) and two worksites had a majority of employees with physically exacting work (the military base and the waste-handling facility). Two worksites were public and two were private and the last one was semi-public. Furthermore, one canteen (the town hall) served organic meals and has an official organic certification. None of the five canteens was run on a for-profit basis and they were all financially supported by the worksite (the military base worksite to a lesser extent than the other four worksites).

\section{Changes at the worksites and the canteens from baseline to long-term follow-up}

The average number of customers in the worksite canteen at baseline and long-term follow-up is shown in Table 1. In general, all five worksites had fewer customers on average at the long-term follow-up measurement compared with the baseline measurement. There were different reasons for fewer customers at the 5-year follow-up compared with the baseline. There were fewer external customers working at the electronic component distributor, the waste-handling facility and the town hall. The electronic component distributor and the bank downsized, and the military base reduced its numbers due to organisational change.

At baseline, four of the worksites had a cash system, where customers selected and purchased different items for lunch, and one had a buffet system, where a variety of food choices were offered at a fixed price. At the 5-year follow-up assessment, four out of five worksites had a buffet system and only one kept the cash system (the military base). All five canteen managers and the majority of the staff at all five worksites were the same at the 5-year follow-up measurement as at the baseline study. One of the worksites (the bank) had outsourced the canteen facility to an external catering company but kept the canteen manager and almost all staff in-house. Another worksite (the waste-handling facility) had an external caterer to cater the lunch and in-house staff to serve lunch and a third worksite (the military base) had a request for proposal to contract out the business.

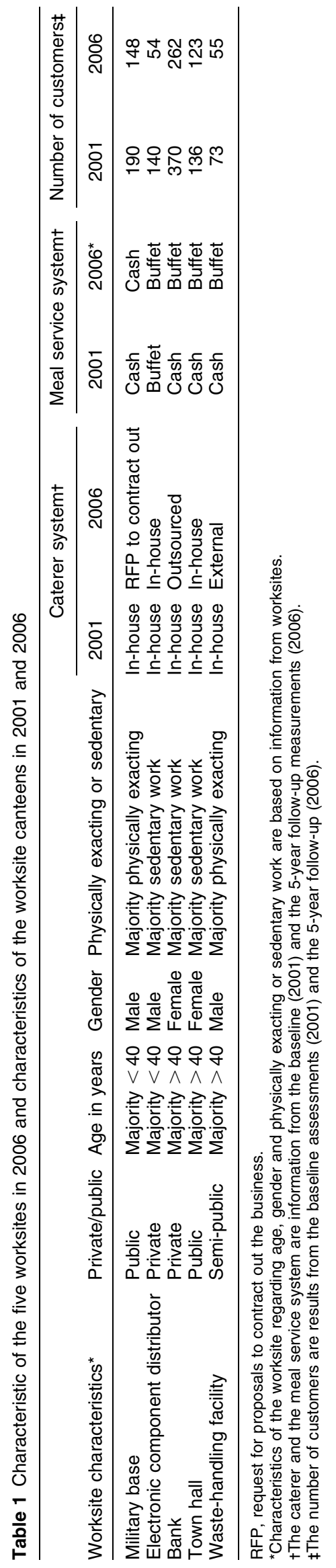




\section{Consumption of fruit and vegetables}

Table 2 shows the total lunch F\&V consumption per customer over time for each of the five worksites. In one case (the waste-handling facility), food was only weighed for 2 weeks ( $n$ 10) due to inadequate canteen staff capacity and holidays. The staff at the remaining four canteens monitored the F\&V during the 3 weeks ( $n$ 15).

On average, the canteens at the baseline had an F\&V consumption of $113 \mathrm{~g} / \mathrm{meal}$ per customer $(69,168,112,118$ and 99, respectively), which increased to an average of $181 \mathrm{~g} /$ meal per customer $(P<0 \cdot 001$ for four worksites and $P=0 \cdot 01$ for the electronic component distributor) at the end point (139, 222, 151, 205 and 192, respectively). The average $\mathrm{F} \& \mathrm{~V}$ consumption at the 5-year follow-up was maintained at the level of $208 \mathrm{~g} /$ meal per customer $(87,312$, 178, 223 and 240, respectively). Overall, a net average increase of $95 \mathrm{~g}$ of $\mathrm{F} \& \mathrm{~V}$ per customer per day was achieved from baseline to the 5-year follow-up measurements for the five worksites. One of the worksites (the military base) failed to sustain the increase in F\&V consumption obtained from the baseline to the end point. At the military base, an insignificant increase of $18 \mathrm{~g}$ per customer per day compared to the baseline was seen $(P=0 \cdot 28)$ at the 5 -year follow-up measurements. All the other four worksites increased the F\&V consumption significantly from baseline to the 5-year follow-up measurements $(P<0 \cdot 001)$.

One of these four worksites further increased $(P<0 \cdot 001)$ its $\mathrm{F} \& \mathrm{~V}$ consumption significantly from both the end point and the 1-year follow-up to the 5-year follow-up measurements (the electronic component distributor increasing from 222 to 228 to finally $312 \mathrm{~g} / \mathrm{meal}$ per customer). As no significant differences in F\&V consumption were seen from the end point to the 5-year follow-up measurements in the bank, the town hall and the waste-handling facility, these worksites sustained the increased F\&V consumption (see Table 2).

\section{Discussion}

The major finding of this long-term sustainability study was that overall the worksite canteens participating in the
' 6 a day' Worksite Canteen Model Study were still, 5 years after the start of the intervention, able to sustain the increased consumption of $\mathrm{F} \& \mathrm{~V}$.

The five canteens on average increased the $\mathrm{F} \& \mathrm{~V}$ consumption from baseline to the 5-year follow-up by $95 \mathrm{~g}$ per meal per customer. However, the present study also showed that some sites were more successful than others. A significant increase from baseline to 5-year follow-up $(P<0 \cdot 001)$ was shown in four out of the five worksites (see Table 2). Only one worksite did not sustain the increased F\&V consumption achieved during the intervention and almost returned to the baseline $F \& V$ intake. Here, F\&V intake decreased by $52 \mathrm{~g} / \mathrm{meal}$ per customer from the end point to the 5-year follow-up measurements $(P=0 \cdot 002)$ and increased insignificantly from the baseline $(P=0 \cdot 28)$.

The sustainability of interventions is found to be a central challenge in public health promotion related not only to the worksite setting, but also in health promotion in general $^{(5,6,8,12,22,23)}$. Relatively few empirical studies are published in this area ${ }^{(7,22,23,27)}$ and the health interventions often fail to consider the programme as complex systems that operate dynamically with the programme, the key stakeholders and the broader community environment ${ }^{(11,12,28)}$

In a review of programme sustainability for health-related programmes in the United States and Canada, the factors contributing to greater sustainability were examined ${ }^{(27)}$. Five factors were found to be important in influencing the extent of sustainability; if a programme can be modified over time, a champion is present, a programme fits with its organisation's mission and procedure, benefits to staff members and/or clients are readily perceived and stakeholders in other organisations provide support. The finding is supported by O'Loughlin et $a l^{(22)}$ when investigating the sustainability of health promotion interventions in qualitative case studies. Furthermore, Lassen et al. ${ }^{(16)}$ suggested similar factors influencing the sustainability of the ' 6 a day' Worksite Canteen Model Study. The method developed during the '6 a day' Worksite Canteen Model Study focused on COoperation between a consultant and the canteen staff and management in defining, planning and implementing the F\&V intervention. The method also focused on providing ideas for increasing F\&V for lunch, making environmental

Table 2 F\&V consumption at baseline, end point, at 1-year follow-up and at 5-year follow-up at each canteen

\begin{tabular}{|c|c|c|c|c|c|c|c|c|c|c|c|c|c|c|}
\hline & \multicolumn{14}{|c|}{ F\&V consumption (g/meal/customer) } \\
\hline & \multicolumn{4}{|c|}{ Baseline intake } & \multicolumn{3}{|c|}{ End-point intake } & \multicolumn{3}{|c|}{ 1-year follow-up intake } & \multicolumn{4}{|c|}{ 5-year follow-up intake } \\
\hline & Mean & SE & $d^{*}$ & $n+$ & Mean & SE & $d^{*}$ & Mean & SE & $d^{*}$ & Mean & SE & $d^{*}$ & $n+$ \\
\hline Military base & $69^{b}$ & 12 & 15 & 190 & $139^{a}$ & 12 & 15 & $147^{\mathrm{a}}$ & 14 & 10 & $87^{b}$ & 12 & 15 & 148 \\
\hline Electronic component distributor & $168^{\mathrm{C}}$ & 12 & 14 & 140 & $222^{\mathrm{b}}$ & 12 & 15 & $228^{b}$ & 12 & 15 & $312^{a}$ & 12 & 15 & 54 \\
\hline Bank & $112^{c}$ & 12 & 15 & 370 & $151^{\mathrm{b}}$ & 12 & 15 & $198^{a}$ & 12 & 15 & $178^{a, b}$ & 12 & 15 & 262 \\
\hline Town hall & $118^{\mathrm{b}}$ & 12 & 15 & 136 & $205^{a}$ & 13 & 13 & $188^{a}$ & 14 & 10 & $223^{a}$ & 12 & 15 & 123 \\
\hline Waste-handling facility & $99^{d}$ & 14 & 10 & 73 & $192^{c}$ & 12 & 15 & $281^{a}$ & 12 & 15 & $240^{\mathrm{b}}$ & 14 & 10 & 55 \\
\hline
\end{tabular}

$\mathrm{a}, \mathrm{b}, \mathrm{c}, \mathrm{d}$ Mean values within a row with unlike superscript letters were significantly different.

*Number of days of monitoring at each canteen.

tNumber of customers at each canteen, results from baseline assesments (2001) and results from 5-year follow-up assessments (2006). 
changes in the canteens by giving access to tasteful and healthy food choices and reducing the availability of unhealthy options ${ }^{(16)}$. We believe that some of the key elements for sustaining this tailored intervention were management involvement, empowering the canteen staff, getting everyone in the canteen involved in a proactive way and providing networking opportunities between canteen managers. Furthermore, the goals and strategies of worksite interventions were decided individually by each of the canteens' staff. All staff members participated in monitoring, goal setting and decision making, which increased their commitment to the project.

It is crucial not only to identify and address barriers but also to enhance facilitators of organisational and environmental changes within worksites ${ }^{(29)}$. The novelty value of the present study lies in the involvement of the canteen staff already in the initial steps of the intervention. In the initial steps, the canteen staff were asked to customise the monitoring procedure of $\mathrm{F} \& \mathrm{~V}$ amounts, to set their own goals and to develop F\&V strategies in the four categories (hot dishes, cold dishes, salad bar and F\&V snacks). The intervention acknowledges that for both the intervention components and outcome measurements to make sense they must be embedded deeply in the daily routines of the staff at the canteen.

The five worksites were different with respect to gender, age, physically exacting/sedentary work (see Table 1). Two worksites were private, two were public and one was semi-public. Four worksites had a buffet meal service system and one had a cash system (the military base). Two worksites had an in-house caterer, two had an external caterer and one had an in-house caterer with a request for proposals to contract out the business (the military base). The F\&V consumption at the canteens at baseline varied from low at the military base $(69 \mathrm{~g} /$ meal per customer) to high at the electronic component distributor ( $168 \mathrm{~g} /$ meal per customer), with an average of $113 \mathrm{~g} /$ meal per customer. Nevertheless, all five worksite canteens succeeded in fulfilling their goals by deciding their own strategies at each canteen reaching at end point an average of $181 \mathrm{~g} /$ meal per customer, and even higher at the 1-year follow-up $(208 \mathrm{~g} / \mathrm{meal}$ per customer). The 5-year follow-up showed that four canteens still sustained, in different ways, the F\&V intervention and that one canteen did not sustain the intervention and almost went back to the baseline. In order to further understand why some of the canteens were more successful than others in sustaining the intervention, qualitative interviews were carried out at all five worksites shortly after the 5-year follow-up measurements. In an upcoming paper, we look more deeply into the differences between the canteens in their ability to sustain the F\&V intervention by analysing the data from a social shaping and a worksite policy process perspective.

Several study limitations should be noted. First, no intake data are available at the individual level. The results are based on the total consumption of F\&V in the canteens relative to the number of customers. It is possible that the results conceal large variations between customers. Other limitations could be the changes in the meal serving system and the decrease in the number of customers. Most of the canteens had changed the serving system from cash system to buffet. This fact may have contributed to the findings and suggest that the positive results may be due not only to the efforts of the canteen staff but also to changes in the food choice pattern of customers due to the introduction of the ad libitum based design of the new serving system. Likewise, changes in the customer base (e.g. more women and more healthconscious customers) may also affect the food choice pattern resulting in healthier food choices and therefore show a sustained or even increased F\&V intake per customer per day. A multivariate analysis of the variables (demographic of the employees and the food service systems) would have strengthened the study in order to support or decline the claim that the intervention was sustained at the 5-year follow-up. Furthermore, the sustained F\&V consumption could be due to more focus during the past 5 years on healthy eating and on health promotion in general in society.

A major strength of the study is that the sustainability data were obtained exactly 5 years after the intervention at a 3-week period, as in the original intervention, in order to avoid seasonal changes in F\&V intake. Furthermore, a 3-week sequential assessment period was chosen to minimise the possibilities of the canteens modifying the meals. In addition, the staff and the management at the canteens were nearly the same as during the intervention, knowing the procedure of the F\&V measurements.

In conclusion, the present study indicates that it is possible to sustain $\mathrm{F} \& \mathrm{~V}$ interventions at the worksite. The study measured the sustainability of the ' 6 a day' Worksite Canteen Model study that was based on a participatory and empowering approach, self-monitoring and networking among worksite canteens. This not only increased F\&V consumption among employees during the intervention period but also contributed to sustaining this increase over the long term. However, not all worksites were equally successful, indicating that more factors influence the sustainability of an intervention. Some factors influencing the sustainability of the intervention could be commitment of the management, outsourcing of the canteen facility and supportive policies at the worksite. The present study indicates that a worksite intervention needs to be tailored to the needs of the particular worksite environment in which it is implemented.

\section{Acknowledgements}

The present study received no specific grant from any funding agency in the public, commercial or not-for-profit 
sectors. None of the authors had any conflicts of interest. The authors thank all staff and management at the five worksite canteens for participating, and for monitoring all F\&V at the canteen for 3 weeks. The authors also thank Anne Marie Beck and Camilla Hoppe from the Department of Nutrition, National Food Institute, Technical University of Denmark for their advice, support and manuscript review and, last but not least, Elizabeth Shieh for her valuable comments, support and manuscript review. A.V.T. and A.D.L. designed the study; A.V.T. carried out the study and drafted the manuscript; A.V.T., A.D.L. and O.H. assisted in analysing the data and contributed to the interpretation and discussion of the results. All authors critically revised the draft manuscript.

\section{References}

1. Nordic Council of Ministers (2006) Health, Food and Physical Activity - Nordic Plan of Action on Better Health and Quality of Life Through Diet and Physical Activity. Copenhagen: Nordic Council of Ministers.

2. Nordic Council of Ministers (2004) Nordic Nutrition Recommendations 2005; Integrating Nutrition and Physical Activity, 4th ed. Nord 2004:13. Copenhagen: Nordic Council of Ministers.

3. World Health Organization (2003) Diet, Nutrition and the Prevention of Chronic Diseases. WHO/FAO Joint Expert Consultation. WHO Technical Report Series no. 916. Geneva: WHO.

4. Alinia S, Hels O \& Tetens I (2009) The potential association between fruit intake and body weight - a review. Obes Rev 10, 639-647.

5. European Commission (2005) Green Paper - Promoting Healthy Diets and Physical Activity: A European Dimension for the Prevention of Overweight, Obesity and Chronic Diseases. COM/2005/0637. Brussels: European Commission.

6. Pomerleau J, Lock K, Knai C et al. (2005) Interventions designed to increase adult fruit and vegetable intake can be effective: a systematic review of the literature. J Nutr $\mathbf{1 3 5}$, 2486-2495.

7. University of Crete School of Medicine (2001) EURODIET Core Report. Nutrition \& diet for healthy lifestyles in Europe: science and policy implications. Public Health Nutr 4, 265-273.

8. Wanjek C (2005) Food at Work: Workplace Solutions for Malnutrition, Obesity and Chronic Diseases. Switzerland: International Labour Organisation.

9. Anonymous (1986) Ottawa Charter for health promotion. Can J Public Health 77, 425-430.

10. Dooris M (2006) Healthy settings: challenges to generating evidence of effectiveness. Health Promot Int 21, 55-65.

11. Shediac-Rizkallah MC \& Bone LR (1998) Planning for the sustainability of community-based health programs: conceptual frameworks and future directions for research, practice and policy. Health Educ Res 13, 87-108.

12. Swerissen H \& Crisp BR (2004) The sustainability of health promotion interventions for different levels of social organization. Health Promot Int 19, 123-130.

13. Whitelaw S, Baxendale A, Bryce C et al. (2001) 'Settings' based health promotion: a review. Health Promot Int 16, 339-353.

14. Buttriss J, Stanner S, McKevith AP et al. (2004) Successful ways to modify food choice: lessons from the literature. Nutr Bull 29, 333-343.

15. Glanz K \& Mullis RM (1988) Environmental interventions to promote healthy eating: a review of models, programs, and evidence. Health Educ $Q$ 15, 395-415.

16. Lassen A, Thorsen AV, Trolle E et al. (2004) Successful strategies to increase the consumption of fruits and vegetables: results from the Danish ' 6 a day' Work-site Canteen Model Study. Public Health Nutr 7, 263-270.

17. Roos E, Sarlio-Lahteenkorva S \& Lallukka T (2004) Having lunch at a staff canteen is associated with recommended food habits. Public Health Nutr 7, 53-61.

18. Sorensen G, Linnan L \& Hunt MK (2004) Worksite-based research and initiatives to increase fruit and vegetable consumption. Prev Med 39, Suppl. 2, S94-S100.

19. Engbers LH, van Poppel MN, Chin AP et al. (2006) The effects of a controlled worksite environmental intervention on determinants of dietary behavior and self-reported fruit, vegetable and fat intake. BMC Public Health 6, 253.

20. Story M, Kaphingst KM, Robinson-O'Brien R et al. (2008) Creating healthy food and eating environments: policy and environmental approaches. Annu Rev Public Health 29, 253-272.

21. Stange KC, Goodwin MA, Zyzanski SJ et al. (2003) Sustainability of a practice-individualized preventive service delivery intervention. Am J Prev Med 25, 296-300.

22. O'Loughlin J, Renaud L, Richard L et al. (1998) Correlates of the sustainability of community-based heart health promotion interventions. Prev Med 27, 702-712.

23. Pluye P, Potvin L \& Denis JL (2004) Making public health programs last: conceptualizing sustainability. Eval Program Plann 27, 121-127.

24. Cook S \& Sinclair D (1997) Emergency department triage: a program assessment using the tools of continuous quality improvement. J Emerg Med 15, 889-894.

25. Robidoux LW \& Sankaran G (1998) Managing nutrition sevices in nursing homes: is continuous quality improvement a key to survival? J Nutr Elder 17, 41-57.

26. Littell RC, Milliken GA \& Stroup WW (1996) SAS ${ }^{\circledR}$ System for Mixed Models. Cary, NC: SAS Institute Inc.

27. Scheirer MA (2005) Is sustainability possible? A review and commentary on empirical studies of program sustainability. Am J Eval 26, 320-347.

28. Gruen RL, Elliott JH, Nolan ML et al. (2008) Sustainability science: an integrated approach for health-programme planning. Lancet 372, 1579-1589.

29. Sorensen G, Linnan L, Hunt MK (2004) Worksite-based research and initiatives to increase fruit and vegetable consumption. Prev Med 39, Suppl. 2, 94-100. 